\title{
INACTIVATION BY OXYGEN AND STABILIZATION BY FLUOROCITRATE OF ACONITASE FROM ESCHERICHIA COLI
}

\author{
YUKIO HATTORI ${ }^{1}$ and SEIICHI HINO \\ Botanical Institute, Faculty of Science, Hiroshima University, Hiroshima
}

(Received September 25, 1980)

\begin{abstract}
More than $50 \%$ of the total aconitase activity in Escherichia coli was lost when cell-free extracts were prepared under air by a French press, by osmotic rupture of spheroplasts or by sonic treatment, as shown by the fact that the enzyme activity of the extracts prepared by sonic treatment under $\mathrm{N}_{2}$ was more than twice that of the extracts prepared by the other methods. When the extracts prepared by sonic treatment under $\mathrm{N}_{2}$ were gently shaken under air at $25^{\circ}$, about 70 to $80 \%$ of the original activity was lost over $30 \mathrm{~min}$, but a constant level of the enzyme activity remained even after prolonged incubation. The remaining aconitase activity after a long aerobic incubation was the same whether the extracts were prepared by sonic treatment under air or $\mathrm{N}_{2}$. Aconitase was stable when cell-free extracts were incubated under anaerobic conditions or when fluorocitrate, in concentrations less than $1 \mu \mathrm{M}$, was added during aerobic incubation. Citrate was less effective than fluorocitrate in preventing enzyme inactivation. Aconitase in the extracts, which had been incubated under air with fluorocitrate, was stable against oxygen inactivation and showed different $V_{\max }$ and $K \mathrm{~m}$ values from those of the aconitase in the extracts that had been incubated under air without the addition of flourocitrate.
\end{abstract}

Aconitase (citrate (isocitrate) hydro-lyase, EC 4.2.1.3) is a member of the tricarboxylic acid cycle group of enzymes and therefore is distributed among almost all respiring organisms. It has been reported that aconitase is unstable and loses activity during preparation or storage $(1,2)$. This loss of activity is known to decrease if the enzyme preparations are kept under anaerobic conditions (1). Most of these studies have been carried out with aconitase samples from eucaryotic cells, particularly those from mammalian cells.

As for aconitase in bacterial cells, some authors compared the enzyme activity between cells under different growth conditions (3-8), and others compared

1 Present address: Department of Physiology, Okayama University Medical School, Okayama 700 , Japan. 
the activity between cells from different growth phases (9). In these studies, cellfree extracts were used to measure aconitase activity. WILKERSON and EAGON (10) pointed out that about $50 \%$ of aconitase activity in extracts from Aerobacter aerogenes was lost during storage for $10 \mathrm{~min}$, while AgRAwAL et al. (11) reported that two isoenzymes of aconitase in sonic extracts from Bacillus cereus $\mathrm{T}$ were both completely inactivated within $30 \mathrm{hr}$ at $30^{\circ}$. Except for these reports, few studies have been reported as to the stability of bacterial aconitase, and generally no particular precaution is taken against oxygen inactivation of aconitase during preparation of cell-free extracts.

During our studies on aconitase of Escherichia freundii, we found that aconitase of this bacterium was so labile to oxygen that sonic disintegration under air led to more than $80 \%$ loss of activity. The extracts prepared under $\mathrm{N}_{2}$ rapidly lost activity if the extracts were gently shaken under air (12).

The present paper describes the results of our studies on the oxygen-sensitivity of aconitase in cell-free extracts from Escherichia coli. The protecting effect of fluorocitrate against oxygen inactivation of aconitase in the extracts is also included.

\section{MATERIALS AND METHODS}

Organism and culture conditions. E. coli $\mathrm{K} 12 \mathrm{~W} 1895$ was grown aerobically for $18 \mathrm{hr}$ in a nutrient broth at $30^{\circ}$, as described by HiNO and MAEDA (13). Cells were collected, washed three times with cold $20 \mathrm{~mm}$ phosphate buffer ( $\mathrm{pH} 7.2$ ) and suspended in the same buffer.

Preparation of cell-free extracts. Unless otherwise indicated, cell-free extracts were prepared by sonic treatment using a Kubota sonic disintegrator Model KMS-100 under $\mathrm{N}_{2}$ as follows: Cell suspensions were transferred to a sonic oscillator vessel, which was sealed with a rubber stopper equipped with a stopcock. After the gas phase of the vessel was changed to pure $\mathrm{N}_{2}\left(\mathrm{O}_{2}\right.$ less than $\left.0.001 \%\right)$ by four successive evacuations and fillings through the stopcock, cells were broken by sonication for $3 \mathrm{~min}$. When indicated, cells were disrupted by the sonic disintegrator under air, using a French press, or by osmotic shock of spheroplasts. For disruption by the press, an Ohtake French Press Model 5615 was used at a pressure of $700 \mathrm{~kg} / \mathrm{cm}^{2}$. Spheroplasts were prepared and ruptured by the following procedures: Thirty $\mathrm{ml}$ of cell suspension ( $0.5 \mathrm{~g}$ wet cells) in a $100 \mathrm{ml}$ Erlenmeyer flask was shaken for $15 \mathrm{~min}$ at $30^{\circ}$ in the presence of $100 \mu \mathrm{g} / \mathrm{ml}$ lysozyme, $400 \mu \mathrm{g} / \mathrm{ml}$ EDTA and $0.6 \mathrm{M}$ sucrose; spheroplasts were recovered, suspended in $20 \mathrm{~mm}$ phosphate buffer ( $\mathrm{pH}$ 7.2) containing $10 \mu \mathrm{g} / \mathrm{ml}$ DNase I, $5 \mathrm{mM} \mathrm{MgCl}_{2}$ and lightly homogenized with a Potter-Elvehjem glass homogenizer.

Cell-free extracts were obtained after unbroken cells and debris were removed by centrifugation at $15,000 \times g$. Unless otherwise indicated, the duration of centrifugation was $5 \mathrm{~min}$. All the operations for obtaining exrtacts, except for 
incubation of cells to make spheroplasts, were carried out in the cold. Extracts were immediately used for assay of enzyme activity or stored at $0^{\circ}$, or incubated at $25^{\circ}$.

Incubation of cell-free extracts. For aerobic incubations, about $3 \mathrm{ml}$ portions of the extracts were poured into an $18 \mathrm{~mm}$ test tube, which was shaken on a reciprocating shaker at 120 strokes per min with an amplitude of $2 \mathrm{~cm}$. At certain time intervals, $0.1 \mathrm{ml}$ of the extracts were removed for enzyme assay. For anaerobic incubation, about $3 \mathrm{ml}$ portions of the extracts were transferred to a Thunberg tube, the gas phase of which was changed to pure $\mathrm{N}_{2}$, and incubated on the shaker. When indicated, fluorocitrate or citrate was added to cell-free extracts during the incubation.

Assay of enzyme activities. The mixture for the measurement of aconitase contained $15 \mathrm{~mm}$ DL-isocitrate, $60 \mathrm{~mm}$ potassium phosphate buffer (pH 7.4), $5 \mathrm{~mm}$ $\mathrm{MgSO}_{4}$, and $0.1 \mathrm{ml}$ cell-free extracts in a total volume of $3.0 \mathrm{ml}$, and the reaction was followed by the increase of absorbance at $240 \mathrm{~nm}(4,14)$.

Reactions were carried out at room temperature in cuvettes of $10 \mathrm{~mm}$ light path with a Shimadzu double beam spectrophotometer model UV-200. Specific activities were expressed as $\mu \mathrm{mol}$ of the product formed per min per mg nitrogen of the extracts. The nitrogen contents of the extracts were determined indirectly using a standard curve drawn between the amount of the protein and nitrogen per $\mathrm{ml}$ of the extracts, assayed by the biuret and a micro-Kjeldahl method, respectively. All the specific activities of the enzymes in this paper are mean values of at least triplicate independent determinations.

Chemicals. DL-Fluorocitrate (barium salt) was purchased from Sigma or Calbiochem. Barium fluorocitrate was dissolved in dilute $\mathrm{HCl}$, and after $\mathrm{BaSO}_{4}$ formed by addition of $\mathrm{H}_{2} \mathrm{SO}_{4}$ was removed by centrifugation, the supernatant was neutralized with $\mathrm{NaOH}$ and used.

\section{RESULTS}

Cell-free extracts were prepared from aerobically grown cells of $E$. coli by the French press, by osmotic disruption of spheroplasts, and by sonic disintegration under air or $\mathrm{N}_{2}$. Table 1 show's that aconitase activity decreased after extracts were stored at $0^{\circ}$ for $10 \mathrm{~min}$. When the extracts were used immediately after preparation, the enzyme activity of the extracts prepared by sonic treatment under $\mathrm{N}_{2}$ was distinctly higher than the activity of the extracts prepared by the other procedures.

When the extracts prepared by sonic disintegration under $\mathrm{N}_{2}$ were shaken under air, aconitase activity rapidly decreased although a certain proportion of the original activity remained even after prolonged aerobic incubation (Fig. 1A). Fluorocitrate was effective for protecting the enzyme from inactivation, citrate to a lesser extent. Tricarballylate and trans-aconitate were not effective for the protection (data not shown). 
Table 1. Aconitase activity of cell-free extracts obtained by different procedures and stored at $0^{\circ}$

\begin{tabular}{lcccc}
\hline & \multicolumn{4}{c}{ Activity $(\mu \mathrm{mol} / \mathrm{min} / \mathrm{mgN})$} \\
Methods of cell disintegration & \multicolumn{2}{c}{ after } & the extracts were stored at $0^{\circ}$ for \\
& 0 & 10 & 30 & $60 \mathrm{~min}$ \\
\hline French press & 1.76 & 1.40 & 0.96 & 0.74 \\
Osmotic rupture of spheroplasts & 1.64 & 1.23 & 0.86 & 0.75 \\
Sonic treatment under air & 1.15 & 0.91 & 0.68 & 0.69 \\
Sonic treatment under $\mathrm{N}_{2}$ & 3.77 & 2.37 & 1.34 & 0.72 \\
\hline
\end{tabular}

The detail of procedures for disintegration is described in the text. Cells and cell debris were immediately removed by centrifugation. The duration of centrifugation after treatment by French press, osmotic rupture, and sonication under air was $10 \mathrm{~min}$, while that after sonication under $\mathrm{N}_{2}$ was $5 \mathrm{~min}$, at $15,000 \times g$. An additional $5 \mathrm{~min}$ was required to stop and open the rotor of the centrifuge. Optical cuvettes placed in the spectrophotometer contained reaction mixtures for aconitase assay except for cell-free extracts, these being added immediately after centrifugation $(0 \mathrm{~min})$ or after the extracts were stored $(5 \mathrm{ml}$ extracts in an $18 \mathrm{~mm}$ test tube) at $0^{\circ}$ for 10 to $60 \mathrm{~min}$.

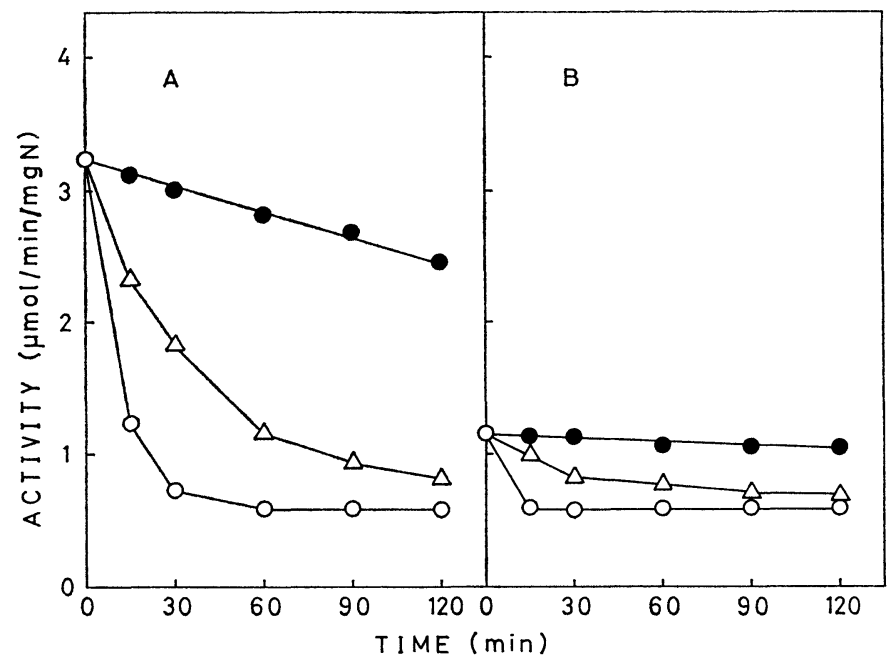

Fig. 1. Effect of fluorocitrate and citrate on inactivation of aconitase by aerobic incubation of cell-free extracts.

Cell-free extracts were prepared by sonic disruption under $\mathrm{N}_{2}(\mathrm{~A})$ or air (B). The extracts were incubated at $25^{\circ}$ under air with $0.01 \mathrm{~mm}$ fluorocitrate $(\bullet), 5 \mathrm{~mm}$ citrate $(\triangle)$, or with neither $(\mathrm{O})$. At time intervals, extracts were withdrawn and tested for aconitase activity.

When extracts were prepared by sonic treatment under air, aconitase activity was originally low and still decreased with aerobic incubation (Fig. 1B). The final levels of aconitase activity after prolonged aerobic incubation were almost the same whether the extracts were prepared under air or $\mathrm{N}_{2}$. Fluorocitrate was also effective in preventing the loss of the activity of aerobically prepared extracts. 
Table 2. Aconitase activity after aerobic or anaerobic incubation of cell-free extracts. Activity: $\mu \mathrm{mol} / \mathrm{min} / \mathrm{mgN}$

\begin{tabular}{ccccccc}
\hline $\begin{array}{c}\text { Gas phase } \\
\text { during } \\
\text { incubation }\end{array}$ & 0 & 15 & 30 & 60 & 90 & $120 \mathrm{~min}$ \\
\hline Air & 3.18 & 1.36 & 0.83 & 0.77 & 0.75 & 0.71 \\
$\mathrm{~N}_{2}$ & & - & 3.17 & 3.17 & 3.11 & 3.04 \\
\hline
\end{tabular}

Cells were sonically disrupted under $\mathrm{N}_{2}$ and the supernatants obtained after centrifugation were incubated under air or $\mathrm{N}_{2}$. At certain time intervals, portions of the extracts were withdrawn and tested for aconitase activity.

Table 3. Effect of ferrous ions and reducing agents in restoring air-inactivated aconitase activity.

\begin{tabular}{lc}
\multicolumn{1}{c}{ Addition } & Relative activity \\
\hline None & 100 \\
$\mathrm{Fe}^{2+}$ & 136 \\
$\mathrm{Cysteine}^{2+}$ and Cysteine & 95 \\
$\mathrm{Fe}^{2+}$ and & 281 \\
$\mathrm{Ascorbate}^{2+}$ and Ascorbate & 101 \\
$\mathrm{Fe}^{2-M e r c a p t o e t h a n o l ~}$ & 188 \\
$\mathrm{Fe}^{2+}$ and 2-Mercaptoethanol & 108 \\
$\mathrm{Glutathione}^{2+}$ and Glutathione & 136 \\
$\mathrm{Fe}^{2}$ Dithioerythritol & 129 \\
$\mathrm{Fe}^{2+}$ and Dithioerythritol & 179 \\
Dithiothreitol & 133 \\
$\mathrm{Fe}^{2+}$ and Dithiothreitol & 244 \\
$\mathrm{Cell}$ & 134 \\
\end{tabular}

Cell-free extracts were incubated under air for $30 \mathrm{~min}$, then ferrous ions (as Mohr's salt; final concentration, $1 \mathrm{~mm}$ ) and reducing agents (final concentration, $5 \mathrm{~mm}$ ) were added, and incubation was carried out for a further $10 \mathrm{~min}$ under air. Relative activities are expressed, taking the activity of the control (without addition of ferrous ions and reducing agents) as 100 . The relative activity of aconitase in extracts before inactivation by air was 516 .

In the remaining part of our experiments, cell-free extracts were prepared by sonic treatment under $\mathrm{N}_{2}$ to avoid inactivation of aconitase during preparation of the extracts.

Table 2 shows aconitase activity of the extracts that were prepared under $\mathrm{N}_{2}$ and subsequently shaken under air or under $\mathrm{N}_{2}$. Aconitase was stable as long as the preparations were kept under anaerobic conditions, but the enzyme activity decreased under aerobic incubation. The enzyme inactivated by exposure to air for $30 \mathrm{~min}$ was incubated for $10 \mathrm{~min}$ with ferrous ions and reducing agents. As listed in Table 3, the activities increased 2- to 3-fold of the inactivated level when the inactivated enzyme preparations were incubated with ferrous ions and reducing agents, such as cysteine, dithioerythritol, or dithiothreitol. The simultaneous presence of ferrous ions and reducing agents was required for the reactivation. 
Several authors have reported that some tricarboxylic acids protect aconitase from inactivation during preparation or storage of the enzyme $(1,2)$. Suzuki et al. (15) found that fluorocitrate, at or less than $50 \mu \mathrm{M}$, remarkably increased the thermostability of yeast aconitase. In the present experiment, fluorocitrate was shown to protect $E$. coli aconitase from oxidative inactivation (Fig. 1A and 1B). Addition of $0.1 \mu \mathrm{M}$ fluorocitrate to cell-free extracts was slightly effective and addition of $1 \mu \mathrm{M}$ almost fully effective in protecting aconitase from inactivation (Table 4). In the experiments in which fluorocitrate was added to cell-free extracts during incubation, some fluorocitrate was carried over with the extracts into the mixture for assay of aconitase activity. Although fluorocitrate is known to be an inhibitor of aconitase, it was confirmed that at concentrations less than $0.1 \mathrm{~mm}$ in incuba-

Table 4. Effect of various concentrations of fluorocitrate in protecting aconitase from inactivation.

\begin{tabular}{ccccccccc}
\hline \multirow{2}{*}{$\begin{array}{c}\text { Before } \\
\text { incubation }\end{array}$} & \multicolumn{10}{c}{ Activity $(\mu \mathrm{mol} / \mathrm{min} / \mathrm{mgN})$} \\
\cline { 2 - 8 } & After incubation with fluorocitrate at a concentration of \\
\hline 3.86 & 0 & $10^{-8.0}$ & $10^{-7.5}$ & $10^{-7.0}$ & $10^{-6.5}$ & $10^{-6.0}$ & $10^{-5.0}$ & $10^{-4.0} \mathrm{M}$ \\
\hline & 0.65 & 0.67 & 0.79 & 1.33 & 2.39 & 3.11 & 3.27 & 3.30 \\
\hline
\end{tabular}

Aconitase activities were measured after cell-free extracts were incubated with various concentrations of fluorocitrate for $60 \mathrm{~min}$ under air.

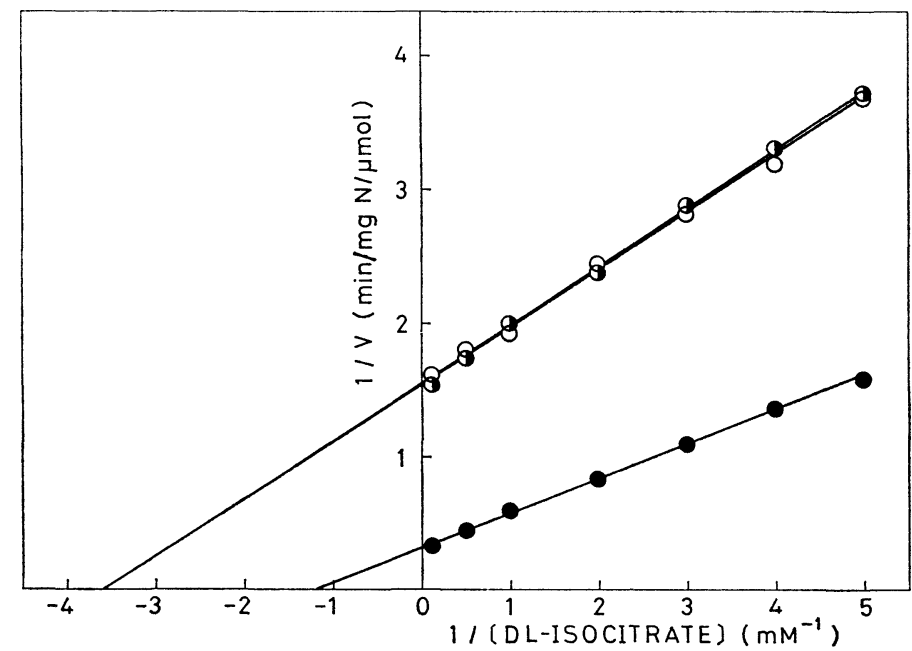

Fig. 2. Double-reciprocal plots between aconitase activity against DL-isocitrate concentration.

Enzyme preparations were cell-free extracts prepared by sonic disruption under $\mathrm{N}_{2}$ and incubated for 60 min under air in the presence $(0)$ or absence $(O)$ of $[10 \mu \mathrm{M}$ fluorocitrate, or incubated for $60 \mathrm{~min}$ under air in the absence of fluorocitrate and further incubated for $60 \mathrm{~min}$ in the presence of $10 \mu \mathrm{M}$ fluorocitrate $(\mathbf{D})$. 
tion mixture, fluorocitrate was not inhibitory to aconitase under the present assay conditions.

Figure 2 shows Lineweaver-Burk plots between reciprocals of aconitase activities against reciprocals of isocitrate concentrations, measured with exrtacts obtained after aerobic incubation in the presence or absence of fluorocitrate. The result indicates that aconitase in extracts, which had been incubated in the presence of $10 \mu \mathrm{M}$ fluorocitrate for $60 \mathrm{~min}$, had a $K \mathrm{~m}$ of $0.84 \mathrm{~mm}$ and $V_{\max }$ of $3.2 \mu \mathrm{mol} /$ $\mathrm{min} / \mathrm{mgN}$, while the enzyme in the extracts that had been aerated without fluorocitrate, had a $K \mathrm{~m}$ of $0.28 \mathrm{~mm}$ and $V_{\max }$ of $0.65 \mu \mathrm{mol} / \mathrm{min} / \mathrm{mgN}$. The result in Fig. 2 also shows that fluorocitrate did not change the $K \mathrm{~m}$ and $V_{\max }$ values of aconitase, if added after the extracts had been aerated for $60 \mathrm{~min}$ in the absence of fluorocitrate.

\section{DISCUSSION}

Although the unstable nature of aconitase has repeatedly been pointed out (1), the results of the present experiments clearly show that aconitase of $E$. coli is so unstable to oxygen that the usual procedures to obtain cell-free extracts, such as disintegration by sonic treatment, by the French press or by osmotic rupture of spheroplasts, lead to considerable air-inactivation of the enzyme. It is necessary to prepare cell-free extracts in the absence of oxygen and use the extracts immediately after preparation, in order to assay aconitase activity of intact cells. Previous addition of fluorocitrate to cell suspensions may be effective in preventing inactivation of aconitase during the preparation of cell-free extracts, since addition of fluorocitrate to the extracts prevented air-inactivation of aconitase therein. Tricarballylate, which was reported to protect aconitase from mammalian cells against inactivation $(1,2)$, was not effective in protecting aconitase from $E$. coli. It was reported that inactivated aconitase from mammalian cells could be reactivated by addition of ferrous ions and reducing agents $(1,2)$. Air-inactivated aconitase from $E$. coli was shown by our study to be also partially reactivated by simultaneous addition of ferrous ions and reducing agents.

Fluorocitrate is known to be an inhibitor of aconitase (I). In the present study it was confirmed that fluorocitrate competitively inhibits aconitase from $E$. coli and that inhibition was negligible at concentrations of less than $10 \mu \mathrm{M}$ under the present assay conditions. The result of the present study also revealed that fluorocitrate at $1 \mu \mathrm{M}$ was effective for protection of aconitase against inactivation. By use of radioactive fluoroacetate, SUzUKI et al. (15) showed that fluorocitrate irreversibly combines with yeast aconitase and stabilizes the enzyme against thermal inactivation. These results suggest that fluorocitrate combines with aconitase from $E$. coli, at a site probably different from the active center of aconitase, and stabilizes the enzyme.

Figure 1 shows that although incubation of extracts under air rapidly inacti- 
vates aconitase, a certain proportion of the original activity remains even after prolonged incubation. The figure also shows that the same level of aconitase activity remained after prolonged aerobic incubation of $E$. coli extracts, regardless of the difference in original activity between the extracts prepared under air or $\mathrm{N}_{2}$. Table 1 shows that extracts prepared by four different procedures gave almost the same activity after the extracts were stored for $60 \mathrm{~min}$. These results suggest the presence of two forms of aconitase in $E$. coli, one is stable and the other is sensitive to oxidative inactivation.

The results of Lineweaver-Burk plots showed that the aconitase in the extracts, which had been in contact with fluorocitrate from the beginning of incubation and was stable to oxygen, gave different $K \mathrm{~m}$ and $V_{\max }$ values from those of the extracts that had not been in contact with fluorocitrate and lost some of the original activity. That fluorocitrate per se does not change the $K \mathrm{~m}$ and $V_{\max }$ values was confirmed by the fact that addition of fluorocitrate after air-inactivation did not change the $\mathrm{Km}$ and $V_{\max }$ values of aconitase in the extracts. The above results could be interpreted that two forms of aconitase with different kinetic behaviors are present in $E$. coli extracts: one form is sensitive to oxidative inactivation but may be stabilized after combination with fluorocitrate, while the other is relatively stable to oxygen. Attempts to separate these two forms of aconitase from extracts of $E$. coli have been unsuccessful, probably because of the extreme instability of one form of the aconitase to oxygen.

The most significant finding of the present study may be that ordinary procedures for obtaining cell-free extracts are not adequate for the assay of intracellular activity of aconitase of $E$. coli. Results that have been published on the activity of aconitase in $E$. coli, and possibly the activity of aconitase from other bacteria, appear to require reexamination.

This study was supported in part by a grant (No. 154224) from the Ministry of Education, Science and Culture of Japan.

\section{REFERENCES}

1) J. P. Glusker, In The Enzymes, Vol. 5, ed. by P. D. Boyer, Academic Press, New York (1971), p. 413.

2) B. FAnsler and J. M. Lowenstein, Methods Enzymol., 13, 26 (1969).

3) C. T. Gray, J. W. T. Wimpenny, and M. R. Mossman, Biochim. Biophys. Acta, 117, 33 (1966).

4) Y. Takahashi and S. Hino, J. Gen. Appl. Microbiol., 14, 429 (1968).

5) J. W. T. Wimpenny and A. M. H. WARMSLey, Biochim. Biophys. Acta, 156, 297 (1968).

6) I. Үамамото and M. Ishimoto, J. Biochem. (Tokyo), 78, 307 (1975).

7) C. W. Keevil, J S. Hough, and J. A. Cole, J. Gen. Microbiol., 113, 83 (1979).

8) A. J. Lewis and J. D. A. Miller, Can. J. Microbiol., 23, 916 (1977).

9) R. S. Hanson, V. R. Srinivasan, and H. O. Halvorson, J. Bacteriol., 86, 45 (1963).

10) L. S. Wilkerson and R. G. EAGon, Arch. Biochem. Biophys., 149, 209 (1972).

11) P. K. Agrawal, G. K. Garg, and K. G. Gollakota, Biochem. Biophys. Res. Commun., 67, 645 (1975). 
12) Y. Hattori and S. Hino, Proc. Annu. Meet. Jap. Soc. Plant Physiol., p. 180 (1979), abstract in Japanese.

13) S. Hino and M. Maeda, J. Gen. Appl. Microbiol., 12, 247 (1966).

14) E. RACKER, Biochim. Biophys. Acta, 4, 211 (1950).

15) T. Suzuki, S. Akiyama, O. Yamazaki, K. Nara, Y. Nakao, and H. Fukuda, Agric. Biol. Chem. (Tokyo), 39, 97 (1975). 